\title{
ANALISIS KEGIATAN EKSTRAKURIKULER PRAMUKA DAN NILAI GOTONG ROYONG SISWA SD PACAR KELING I SURABAYA
}

\author{
Devi Hardianti ${ }^{1)}$, Badruli Martati ${ }^{2)}$, Kunti Dian Ayu Afiani ${ }^{3)}$ \\ ${ }^{1), 2), 3}$ Universitas Muhammadiya Surabaya \\ Corresponding author Email: devi.hardianti-2016@fkip.um-surabaya.ac.id
}

\begin{tabular}{ll}
\hline Kata Kunci: Ekstra & Abstrak \\
Pramuka., Nilai Karakter & Membentuk karakter pada peserta didik yang dewasa agak sulit untuk mewujudkan \\
Gotong Royong & karakter yang baik maka akan lebih baik membentuk karakter anak mulai sejak dini. \\
& Hal tersebut diperlukan pengembangan potensi peserta didik yang bertujuan pada \\
& pendidikan berkarakter dengan melalui program ekstrakurikuler yang merupakan \\
& kegiatan diluar jam pembelajaran. Program ekstrakurikuler ini kegiatan tambahan \\
& yang alokasinya diluar jam pembelajaran tidak ditetapkan pada kurikulum 2013. \\
& Gerakan Pramuka salah satu wadah dan usaha membina karakter generasi mudah \\
& dengan menggunakan pendidikan kepramukaan dapat dilaksanakan sesuai \\
& kepentingan perkembangan siswa sekolah dasar. Kegiatan ekstrakurikuler pramuka \\
akan menerapkan nilai kerja sama yang akan ditanamkan kepada peserta didik, disaat \\
kegiatan ekstra pramuka berlangsung siswa akan membahur dengan siswa yang lain \\
dalam satu tim dimana akan membentuk suatu golongan ditingkat pramuka. Tujuan \\
penelitian ini yaitu untuk menanamkan pembentukan nilai karakter bangsa kepada \\
siswa lebih efektif melalui kegiatan ekstrakurikuler pramuka dengan memperiotaskan \\
nilai kerja sama, suka tolong menolong, sehingga pendidikan karakter gotong royong \\
mampu mengubah perilaku, cara berfikir dan cara bertindak untu menjadikan siswa \\
lebih baik dan berintegrasi.
\end{tabular}

\begin{tabular}{ll}
\hline Keyword: & Abstract \\
$\begin{array}{l}\text { Scout Extras, The } \\
\text { Character Values of } \\
\text { Mutual Cooperation }\end{array}$ & will be better to form children's character from an early age. For this, it is necessary \\
to develop the potential of students who aim at character education through \\
extracurricular programs which are activities outside of learning hours. This \\
extracurricular program is an additional activity whose allocations outside the \\
learning hours are not stipulated in the 2013 curriculum. The Scout Movement is one \\
of the places and efforts to foster the character of the easy generation by using \\
scouting education to be implemented according to the interests of the development \\
of elementary school students. Scout extracurricular activities will apply the value of \\
cooperation that will be instilled in students. When the extra scouting activities take \\
place students will discuss with other students in a team which will form a group at \\
the scout level. The purpose of this article is to instill the formation of national \\
character values in students more effectively through scout extracurricular activities \\
by emphasizing the value of cooperation and solidarity. Mutual cooperation can \\
change behavior, ways of thinking and how to act to make students better and \\
integrated.
\end{tabular}
@ Inventa: Jurnal Pendidikan Sekolah Dasar Copy Right 


\section{Pendahuluan}

Dimasa sekarang ini yang terjadi membuat masyarakat Indonesia terlupa akan pentingnya pendidikan karakter bangsa. Akibat yang ditimbulkan juga didukung oleh kemajuan teknologi tersebut dapat mempengaruhi dampak yang positif, melainkan juga banyak dampak negatif yang telah timbul pada era globalisasi yaitu degradasi nilai atau moral yang terjadi pada saat ini, terdapat berbagai kasus misalnya terjadi sentiment pada etnis, perselisahan suku bangsa, narkoba, tawuran sesama pelajar, kekerasan dibawah umur, perampokan, dan kasus penghinaan. Demikian, rendahnya kesadaraan masyarakat untuk menerapkan nilai moral yang ada dalam kehidupan sehari hari dan menunjukan bahwa karakter pada kebangsaan kita lemah. Pembentukan karakter dibentuk mulai sejak kecil untuk menumbuhkan karakter jiwa bangsa yang baik dan membangun generasi mudah yang baik. Mendidik siswa yang berkarakter, didasarkan pada nilai - nilai pendidikan karakter yang ditanamkan oleh seorang guru untuk siswa seperti: religus, jujur, toleransi, disiplin, kerja sama, kreatif, mandiri, demokratif, rasa ingin tahu, semangat kebangsaan, cinta tanah air pada bangsa, menghargai prestasi orang lain, menjalakan bersahabat dengan berkomunikasi dengan baik, cinta damai, gemar membaca, peduli lingkungan masyarakat, peduli sosial dan tanggung jawab pada lingkungan sekitar.
Tujuan pendidikan yang tercantum dalam undang - undangan Nomor 20 Tahun 2003 tentang Sistem Pendidikan Nasional

"Pendidikan nasional berfungsi mengembangkan kemampuan dan membentuk watak serta kultur kebangsaan yang bermartabat dalam mencerdaskan kehidupan bangsa, bertujuan untuk berkembangnya potensi peserta didik agar menjadi manusia yang beriman bertaqwa kepada Tuhan Yang Maha Esa, berakhlak mulia, berilmu, cakap kreatif, mandiri dan bertanggung jawab".

Pembentukan karakter saat ini membutuhkan proses yang tiada henti karakter akan dijadikan komponen yang sangat penting bagi seorang siswa untuk membangun generasi mudah yang baik, sehingga karakter pada peserta didik sangat penting untuk menentukan sikap dan perilaku seorang. Membentuk karakter pada peserta didik yang dewasa agak sulit untuk mewujudkan karakter yang baik maka akan/lebih baik membentuk karakter anak mulai sejak dini. Maka diperlukan pengembangan potensi peserta didik yang bertujuan pada pendidikan berkarakter dengan melalui program ekstrakurikuler yang merupakan kegiatan diluar jam pembelajaran. Program ekstrakurikuler ini kegiatan tambahan yang alokasinya diluar jam pembelajaran tidak ditetapkan pada kurikulum 2013. Demikian ini, program ekstrakurikuler pramuka merupakan kegiatan wajib pada pendidikan sekolah dasar. Kegiatan ini tersebut untuk membentuk siswa - siswi yeng berbeda seperti 
pada sikap moral yang berbeda, nilai kemampuan, dan kreativitas, dapat berpatisipasi dalam program ekstrakurikuler peserta didik dapat belajar dan mengembangkan kemampuan berkomunikasi, bekerja sama dengan orang lain. Menurut (Mufti, 2017:5) Gerakan Pramuka salah satu wadah dan usaha membina karakter generasi mudah dengan menggunakan pendidikan kepramukaan dapat dilaksanakan sesuai kepentingan perkembangan siswa sekolah dasar.

Ekstrakurikuler adalah pendidikan non akademik yang dapat dilaksanakan oleh siswa SD, SMP, SMA/SMK dan Mahasiswa Perguruan Tinggi yang dilaksanakan pada waktu diluar pembelajaran K13. Program ekstrakurikuler ditunjukan kepada siswa untuk mengembangkan prestasi dan kompotensi macam - macam bidang non akademik dan membentuk suatu karakter yang baik.

Program ekstrakuriler wajib di sekolah yaitu: Gerakan Pramuka, Menurut (Tjendrawidjaja, 2018:5) mengatakan, Gerakan Pramuka adalah Gerakan (lembaga) Pendidikan yang komplementer dan suplementer (melengkapi dan memenuhi pendidikan yang diperoleh anak/remaja/pemuda dirumah dan disekolah), pada segmenyang belum ditangani oleh lembaga pendidikan lain yang pelaksanaanya menggunakan prinsip dasar pendidikan kepramukaan dan metode pendidikan kepramukaan di alam terbuka (outdoor activites).

Kegiatan ekstrakurikuler pramuka yaitu proses pendidikan yang melengkapi pendidikan dilingkungan sekolah dan lingkungan keluarga dalm bentuk kegiatan menarik. Pramuka yaitu anggota gerakan pramuka yang terdiri dari anggota muda seperti peserta didik S, G, T, D dan anggota dewasa contohnya Pembina pramuka, pembantu Pembina, pelatih pembina pramuka, Pembina professional, dan lain - lain.

Peraturan Menteri Pendidikan dan Kebudayaan RI No. 81 Tahun 2013 tentang Implementasi Kurikulum tentang Sistem Pendidikan Kurikulum yaitu seperangkat rencana dan pengaturan mengenai tujuan, isi dan bahan pembelajaran untuk mencapai tujuan pendidikan tertentu, yang bermakna kuikulum konsep terpadu, peserta didik akan memahami konep-konsep yang akan mereka pelajari itu utuh dan realistis. Upaya implementasi kurikulum 2013, pendidikan karakter dapat di integrasikan dalam pembelajaran yang berkaitan dengan norma atau nilai - nilai setiap bidang studi perlu dikembangkan langsung pada pembelajaran berlangung, dalam kehidupan sehari-hari. Kurikulum sebagai penguatan karakter siswa yang telah diperkuat oleh Peraturan Presiden Nomor 87 Tahun 2017 tenntang Pendidkan Karakter (PPK). Dengan demikian guru dituntut untuk melakukan penguatan karakter 
pada siswa dengan menginternalisasikan nilainilai utama PPK yaitu, religiusitas, nasionalisme, mandiri, gotong royong, dan integritas dalam setiap kegiatan pembelajaran yang dilaksanakan. Nilai Religusitas yaitu: beriman dan bertaqwa kepada Tuhan Yang Maha Esa, taat beribadah, bersyukur, dan berdoa. Nilai Nasionalisme yaitu: cinta tanah air, semangat kebangsaan, menghargai kebhinekaan, menghayati lagu nasional. Nilai Kemandiran yaitu: disiplin, percaya diri, rasa ingin tahu, tangguh, bekerja keras, mandiri, dan kreatif inovatif. Nilai Gotong Royong yaitu: suka menolong, bekerja sama, peduli sesama, toleransi, peduli lingkungan, kebesihan dan kerapian, kekeluargaan, aktif dalam kegiatan masyarakat, (Peraturan Menteri Pendidikan dan Kebudayaan Republik Indonesia Nomor 81A Tahun 2013. Implementasi Pendidikan:26)

Hasil observasi penelitian tersebut pada tanggal 18 Januari 2020 terhadap dilingkungan SD Pacar Keling I Surabaya, siswa cenderung kurang solidaritas dalam bergotong royong terhadap sesama teman. Meskipun pada waktu ekstrakurikuler pramuka berlangsung Pembina menyuruh siswa untuk berkolaborasi dengan teman - temannya, siswa tersebut masih berindividual dan masih pilih - pilih teman mana teman yang pandai atau tidak pandai. Ketika kakak Pembina mengasih tugas kelompok kepada siswanya hanya satu dua orang yang mengerjakannya tugas tersebut, anggota kelompok yang lain hanya bermain sendiri - sendiri diluar lapangan.

Sehingga siswa yang sedikit ikut serta dalam bekerja sama dalam kegiatan gotong royong dan juga banyak siswa yang menggapan kegiatan gotong royong disepelkan oleh siswa hal ini kurangnya guru mengajar didalam kelas kurang menerapkan kurikulum 2013 yang bernilaikan PPK, disaat pembelajaran berkelompok berlangsung, maka dilihat dari segi cara berkelompok pada siswa guru belum menerapkan kurikulum yang mengimplementasikan PTK bernilai gotong royong ketika proses pembelajaran berlansung. Pada seorang anak yang belum berperan dalam kegiatan gotong royong akan mendapatkan pengaruh buruk pada kehidupan masyarakatnya di masa beranjak dewasa, berakibatnya kurang kerja sama dengan orang lain. Pentingnya peran seorang guru untuk menerapkan sikap gotong royong kepada siswa dan keteladanan dalam melaksanakan kegiatan gotong royong dikelas atau diluar kelas agar peserta didik dapat mengaplikasikannya dalam kehidupan sehari hari disekitar lingkungan. Peran utama seorang guru yaitu mewujudkan keberhasilan pendidikan sesuai dengan tujuan pendidikan nasional. Oleh karena itu sangat penting penanaman karakter gotong royong pada siswa untuk mengembangkan sikap, sosial, atau peduli terhadap lingkungan. 
Dari latar belakang ekstrakurikuler Pramuka sebagai wadah dalam pembinaan serta penanaman sikap gotong royong pada anak. Dengan memperhatikan dan melihat kenyataan penelitian berminat untuk meneliti sekaligus menyusun skripsi dengan judul Analisis Kegiatan Ekstrakurikuler Pramuka dan Nilai Gotong Royong Siswa Kelas V SD Pacar Keling 1 Surabaya. Tujuan penelitian ini yaitu untuk menanamkan pembentukan nilai - nilai karakter bangsa kepada siswa lebih efektif melalui kegiatan ekstrakurikuler pramuka dengan memperiotaskan nilai kerja sama, suka tolong menolong, sehingga pendidikan karakter gotong royong mampu mengubah perilaku, cara berfikir dan cara bertindak untu menjadikan siswa lebih baik dan berintegrasi

\section{Metode Penelitian}

Jenis penelitian ini yaitu menggunakan penelitian deskriptif kualitatif Sugioyono (2012:205) karena dilakukan untuk mengamati suatu permasalahan secara sistematis dan tepat mengenai fakta dan objek pada topic tertentu, penelitian kualitatif deskriptif memaparkan dalam bentuk kalimat mengenai apa saja yang dialami oleh subjek penelitian. Penelitian dilaksanakan di SDN Pacar Keling 1 Surabaya pada siswa kelas 5. Penelitian dilakukan pada bulan Januari sampai Mei 2020. Teknik pengumpalan data menggunakan angket terbuka, wawancara, dokumentasi dan observasi. Angket terbuka akan dibagikan pada 15 responden perwakilan dari kelas $\mathrm{V}$ melalui google from dengan link https://docs.google.com/forms/d/e/1FAIpQLS cyvVyK7-Z5Mio4-

x4m99s55iO1SMFnfsmQAnQHVt-

$\underline{\mathrm{P} 6 X X Y 2 \mathrm{~g} / \text { viewform? } \mathrm{usp}=\mathrm{sf} \text { _link. }}$

Teknik observasi ini digunakan untuk memperoleh data secara langsung perilaku sikap gotong royong siswa kelas $\mathrm{V}$, dengan tujuan untuk mendapatkan data lapangan yang bersifat umum kemudian mengerucut dan lebih rinci terhadap permasalahan yang ingin ditanyakan sesuai dengan rancangan yang dibuat. Teknik analisis data menggunakan model Miles and Huberman yang dilakukan pada saat pengumpulan data berlangsung dan setelah pengumpulan data. Miles and Huberman dalam (Sugiyono,2015:246), mengemukakan bahwa aktivitas dalam analisis data kualitatif dilakukan secara interaktif dan berlangsung secara terus menerus sampai tuntas. Model teknik analisis data lapangan Miles and Hubermas yaitu reduksi Data (Data Reduction) proses pemilihan, pemutusan perhatian pada penyederhanan dan transformasi data kasar yang diperoleh dilapangan, penyajian data (Data Display) kumpulan informasi tersusun yang memungkinkan untuk melakukan penarikan kesimpulan dan pengabdian tindakan, penarikan kesimpulan (Conclusion Drawing/Verification). Menurut (Sugiyono 
2015:273) teknik keabsahan data peneliti dengan cara mengecek data telah diperoleh melalui berbagai sumber, dan triangulasi metode yaitu untuk menguji kredibilitas data yang dilakukan dengan cara mengecak data pada sumber yang sama dengan menggunakan metode yang berbeda misalnya data diperoleh hasil wawancara, lalu di cek dengan hasil observasi dan hasil dokumentasi atau kuesioner. Penelitian ini meneliti di lokasi SDN PacarKeling 1 Surabaya jalan Tambang Boyo waktuk untuk meneliti pada tanggal 18 Januari s/d 20 Mei.

\section{Hasil Penelitian dan Pembahasan}

Hasil Penelitian ini dimaksudkan untuk mengidentifikasi dan menganalisis kegiatan ekstrakurikuler pramuka yang sedang berlangsung terutama dalam karakter nilai gotong royong. Dalam penelitian ini beberapa siswa belum ditanamkan sikap karakter nilai gotong royong, untuk mendapat informasi maka dilakukan identifikai dengan cara observasi, wawancara, penyebaran angket dan dokumentasi. Tahap perencanan pada penelitian ekstrakurikuler pramuka, penelitian melakukan tahap observasi dan tahap penyebaran angket. Pada tahap penyebaran angket yang bersifat terbuka melalui google from ada 14 responden yang akan menjawab angket tersebut dalam perwakilan 2 kelas.

\begin{tabular}{|c|c|c|c|}
\hline \multicolumn{4}{|c|}{ Tabel 1. Hasil Penelitian } \\
\hline \multirow{3}{*}{ Indikator } & \multirow{3}{*}{$\begin{array}{c}\text { Nama } \\
\text { Responden }\end{array}$} & \multirow{2}{*}{\multicolumn{2}{|c|}{$\begin{array}{c}\text { Jawaban } \\
\text { Pertanyaan }\end{array}$}} \\
\hline & & & \\
\hline & & yа & Tidak \\
\hline \multirow{26}{*}{$\begin{array}{l}\text { Terlibat aktif } \\
\text { dalam } \\
\text { menyelesaikan } \\
\text { tugas - tugas } \\
\text { kelompok }\end{array}$} & M Alfian & $v$ & \\
\hline & Wijaya Putra & & \\
\hline & Ibrahim raja & & $v$ \\
\hline & nirwana & & \\
\hline & Athalia Asakta & & $v$ \\
\hline & Harjanni & & \\
\hline & Jihan nabilla & $v$ & \\
\hline & al'ililyin & & \\
\hline & Aira festi & $v$ & \\
\hline & fabriana & & \\
\hline & Agil noval & $v$ & \\
\hline & prasetyo & & \\
\hline & Bilqis Intan & $v$ & \\
\hline & Kameliya & & \\
\hline & Chearyl Aulia & & $v$ \\
\hline & Davin Ukar & & $v$ \\
\hline & Hartono & & \\
\hline & Deslita Aisyah & $v$ & \\
\hline & Faihtoni Afif & & $v$ \\
\hline & Fania Arum Sari & $v$ & \\
\hline & Farrel Daffa & $v$ & \\
\hline & Pedrosa & & \\
\hline & Febrianto Agung & & $v$ \\
\hline & Key Romeo & $v$ & \\
\hline & Denvls Siswa & & \\
\hline & Usman & & \\
\hline & & 9 & 6 \\
\hline
\end{tabular}

Hasil angket $45 \%$ menyatakan bahwa siswa aktif dalam berkelompok dan berkerja sama terhadap kelompok, 5\% siswa masih berindividual jika bekerja sama dengan satu kelompok.

Pembahasan dalam penelitian ini, Kegiatan ekstrakurikuler pramuka pada nilai gotong royong di SD Pacar Keling 1 Surabaya berdasarkan dari GUDEP (Gugus Depan). Hasil wawancara oleh Kambigus SD Pacar 
Keling 1 Surabaya dengan Pembina satuan penggalang cara penyampaian sejalan.

"Kami Pembina penggalng satuan pada ekstra pramuka untuk menanamkan sikap karakter gotong royong memberikan materi pembelajaran di dalam buku panduan SKU yang dimiliki oleh siswa serta mencontohkan sikap gotong royong atau kerja sama yang diterapkan oleh siswa ketika pelaksanaan kegiatan berlangsung agar siswa - siswa dapat membaur dengan siswa yang lain tidak

Guru atau Pembina Pramuka melakukan tugas sesuai dengan tanggung jawabnya dan memberikan tugas materi yang pada di SKU (Syarat Kecakapan Umum) dan SKK (Syarat Kecakapan Khusus), didalam SKU terdapat materi yang bernilaikan sikap gotong royong yang bisa diterapkan kepada peserta didik kita. Pada kegiatan ekstrakurikuler pramuka akan menerapkan nilai kerja sama yang akan ditanamkan kepada peserta didik, disaat kegiatan ekstra pramuka berlangsung siswa akan membahur dengan siswa yang lain dalam satu tim dimana akan membentuk suatu golongan ditingkat pramuka.

Penugasan yang akan dilaksanakan kepada peserta didik untuk membuat dua proyek yang pertama siswa akan membuat sebuah pionering untuk mengibarkan bendera merah putih secara bersama - sama di halaman sekolah, yang kedua siswa akan mendirikan sebuah tenda darurat pada waktu kita perjalanan malam dialam terbuka untuk kita berteduh dan melindungi diri dari hewan liar pada gambar 3.1 membuat bivak/tenda darurat.
Ada juga penugasan secara online yaitu mengerjakan secara kelompok dimana tugas tersebut mengartikan atau menerjemahkan sandi - sandi yang sudah pada link digoogle. Pada kelompok yang aktif Pembina akan mengaih reward berupa TKK (Tanda Kecakapan Khusus) menjadi regu giat. Gambar 3.2.

\section{Hasil Wawancara Kamabigus SD Pacar} Keling 1 Surabaya dengan Pembina Satuan Penggalang.

"Guru disini rata - rata sudah mendapatkan ijazah KMD ada yang sudah melanjutkannya narakarya sehingga mendapatkan ijazah KML yang ditempuh setahun, nanti pembina yang mudah mudah ini saya suruh sampai KML"

Kemampuan guru atau Pembina di SD Pacar Keling 1 Surabaya dalam melaksanakan kegiatan pramuka sangat baik dan mayoritas sudah mengikuti pelatihan KMD (Kursus Mahir Dasar) dan ada juga yang telah mengikuti KML (Kursus Mahir Lanjut). Ekstrakurikuler yaitu Program tambahan yang dilaksanakan pada waktu diluar jam pembelajaran yang baik disekolah atau diluar sekolah bertujuan untuk mendapatkan pengetahuan secara luas, keterampilan berfikir dan wawasan serta membantu membentuk karakter pada siswa sesuai minat dan bakat, pada umunya eskstrakurikuler pramuka wajib bagi peserta didik agar berwawasan, sikap dan juga kepribadian yang baik dalam 
pembentukan karakter pada peserta didik.Program ekstrakurikuler pada sekolah terbagi menjadi ekstrakurikuler wajib dan ekstrakurikuler pilihan. Kegiatan ekstrakurikuler pramuka merupakan ekstrakurikuler wajib dilakukan oleh setiap siswa mulai dari SD, SMP, SMA/SMK kecuali memiliki kekhususan (Gultom, 2014:6).

"Ekstrakurikuler wajib merupakan program ekstrakurikuler yang harus diikuti oleh seluruh peserta didik terkecuali bagi peserta didik dengan kondisi tertentu yang tidak memungkinkan untuk mengikuti kegiatan ekstrakurikuler tersebut".

Tujuan dari adanya Gerakan pramuka yaitu membentuk suatu kepribadiaan kepada peserta didik memiliki pribadi yang berjiwa patriot, beriman dan bertaqwa, akhlak mulia, disiplin dan menjunjung nilai - nilai luhur bangsa dan memiliki kader bangsa dalam menjaga membangun Negara Kesatuan Republik Indonesia, mengamalkan nilai Pancasila dan melestarikan lingkungan sekitar.

Hasil wawancara kamabigus dan Pembina penggalang satuan SD Pacar Keling 1 Surabaya

"disekolahan ini terdapat ruang sanggar pada lantai 2, didalam sanggar terdapat perlalatan pramuka yang lengkap seperti tenda, tongkat, tali, semaphore dan lain lain"

Kebutuhan Sarana dan Prasarana SD Pacar Keling 1 Surabaya untuk kegiatan pramuka sudah cukup memadai, semua peralatan sudah tersedia dan lengkap di dalam ruang sanggar yang letaknya di lantai 2. Dalam sistem pendidikan Undang - Undang Nomor 20 Tahun 2003 tentang standar sarana dan prasarana yang dimana harus terpenuhi.

Hasil Penelitian di dukung oleh Helen Alison Dollery Tahun 2012 Making, happy, healty, helpful citizens: The New Zealand Scouting and Guiiding Movements as Promulgators of Active Citizenship, c.1908 1980. Tesis ini membahas tentang Selandia Baru Pramuka dan peran mereka dalam mengembangkan kegiatan kepramukaan. Sebagai organisasi sukarela gerakan beroperasi dan sangat terlibat dengan masyarakat Selandia Baru yang lebih luas, berinteraksi dengan lembaga negara dan sipil, dan dengan masyarakat. Pramuka secara aktif memberikan kontribusi kepada masyarakat di tingkat lokal, nasional dan internasional.

Dari pihak sekolah terlibat dalam evaluasi kegiatan ekstrakurikuler Pramuka di SD Pacar Keling 1 Surabaya yaitu kamabigus, mabigus dan dukungan dari dewan guru, terkait evaluasi kegiatan Kegiatan ekstra pramuka ini dilakukan dalam satu minggu sekali pada waktu selesai jam kegiatan belajar mengajar di dalam kelas. Pendidikan dalam Gerakan Pramuka diartikan secara umum adalah suatu proses pembinaan dan pengembangan sepanjang hayat yang berkesinambungan atas kecakapan yang dimiliki peserta didik, baik dia sebagai pribadi 
maupun sebagai anggota masyarakat. Sasaran pendidikan dalam arti luas tersebut adalah menjadikan peserta didik sebagai manusia yang mandiri, peduli, bertanggungjawab dan berpegang teguh pada nilai dan norma masyarakat. Pendidikan dalam arti luas bertumpu pada empat sendi atau "soko guru" Menurut (tjendrawidjaja 2018) yaitu:

1. Belajar mengetahui (Learning to know) untuk memiliki pengetahuan umum yang cukup luas dan untuk dapat bekerja secara mendalam dalam beberapa hal. Ini juga mencakup belajar untuk belajar, agar dapat memanfaatkan peluang-peluang pendidikan sepanjang hidup.

2. Belajar berbuat (Learning to do) bukan hanya untuk memperoleh kecakapan/ketrampilan, kerja, melainkan juga untuk memiliki ketrampilan hidup yang luas, termasuk hubungan antar pribadi dan hubungan antar kelompok.

3. Belajar hidup bermasyarakat (Learning to live together) untuk menumbuhkan pemahaman terhadap orang lain, menghargai, saling ketergantungan, ketrampilan dalam kerja kelompok dan mengatasi pertentangan-pertentangan, serta menghormati sedalam-dalamnya nilai-nilai kemajemukan (pluralism), saling pengertian, perdamaian dan keadilan.
4. Belajar untuk mengabdi (Learning to serve) agar peduli terhadap sesama dan alam semesta.

5. Belajar menjadi seseorang (Learning to be) untuk mengembangkan watak dan kepribadian sehingga mempunyai sikap mandiri, tegas, prinsip, nalar, dan berani mengemukakan pendapat serta bertanggungjawab.

Hasil wawancara dengan Kamabigus dan Pembina satuan SD Pacar Keling 1 Surabaya

"anak - anak sini untuk kehadiran sedikit bermasalah kadang sudah jam ekstra Pembina keliling kelas masing2 dan lagi siswa yang bolos ekstra khususnya cowok kadang sembunyi dikanti atau dikelas 
siswa lebih antusia mengikuti ekstra pramuka ini. dampak positifnya dari penerapan sikap gotong royong yaitu lebih disiplin, saling tolong menlong, kemandirian dan lebih menambah wawasan dibidang.

Hasil Penelitian ini di dukung oleh Mafardi Tahun 2017 Nilai - Nilai Karakter dalam mata pelajaran muatan lokal budaya. Jurnal ini membahas tentang bahwa pendidikan merupakan wadah penyiapan anggota masyarakat, jdai sumber daya manusia yang berkualitas yang relevan dengan tuntunan masyrakat lingkungan sekitar sekolah dan lingkungan yang lebih besar yaitu bangsa dan negara.

Kendalanya yaitu yang pertama siswa masih datang terlambat dan Pembina yang harus datang ke masing kelas untuk turun ke lapangan kegiatan ekstra pramuka segera dimulai, siswa kurang kerja sama saat berkelompok, kurang disiplin disaat kegiatan ekstra pramuka berlangsung dan belum fokus dalam materi yang disampaikan oleh kakak Pembina, cuacanya panas dan hujan menjadi penggalang siswa untuk pramuka ditempat lapangan yang terbuka. Ketika salah satu Pembina yang tidak hadir bisa menggantikan Pembina pramuka yang lain untuk mengisi materi selanjutnya atau bahas materi sebelumnya yang masih belum mengerti bagi siswanya. Menurut (tjendrawidjaja 2018) Metode Pendidikan Kepramukaan adalah penyamapain pendidikan kepada peserta didik melalui kegiatan Pendidikan Pramuka yang menarik, menyenangkan dan menantang, yang disesuaikan lingkungan sekitar, suasana pada kegiatan peserta didik. Metode Pendidikan Kepramukaan merupakan cara belajar progresif melalui:

1. Pengamalan Kode Kehormatan Pramuka;

2. Belajar sambil melakukan (Learning by doing);

3. Kegiatan berkelompok, bekerjasama dan berkompetensi (patrol system);

4. Kegiatan yang menarik menantang

5. Kegiatan di alam terbuka;

6. Kehadiran orang dewasa dalam setiap kegiatan;

7. Pengharaan berupa tanda kecakapan;

8. Sistem satuan terpisah untuk putra dan puteri;

9. Kiasan dasar;

Upaya mencegah kendala dalam kegiatan yaitu sebelum KBM daring melaksanakan kegiatan eskul daring dengan waktu 2 jam, teman yang tidak mempunyai alat komunikasi bisa tanyak kepada teman kelasnya yang dekat dari rumah, tugas yang diberikan oleh Pembina yang mengandung unsur nilai gotong royong atau kerja sama. Selama menjalani distancing proses kegiatan ekstra tetap berjalan seperti biasa akan tetapi peserta didik melakukan sebuah proyek pembuatan video yang dilakukan dirumah dan dapat arahan atau bimbingan dari Pembina, proyek tersebut melalui di chanel youtube 
sekolah pribadi agar siswa tidak jenuh pada saat kegiatan ekstra pramuka. Kepramukaan yaitu pendidikan pada waktu diluar jam pembelajaran sekolah dan keluarga dalam kegiatan yang menarik, menyenangkan, tantangan di alam terbuka agar membina watak siswa tersebut.

\section{Kesimpulan dan Saran}

Kegiatan ekstrakurikuler pramuka akan menerapkan nilai kerja sama yang akan ditanamkan kepada peserta didik, disaat kegiatan ekstra pramuka berlangsung siswa akan membahur dengan siswa yang lain dalam satu tim dimana akan membentuk suatu golongan ditingkat pramuka. Tujuan dari adanya Gerakan pramuka yaitu membentuk suatu kepribadiaan kepada peserta didik memiliki pribadi yang berjiwa patriot, beriman dan bertaqwa, akhlak mulia, disiplin dan menjunjung nilai - nilai luhur bangsa dan memiliki kader bangsa dalam menjaga membangun Negara Kesatuan Republik Indonesia, mengamalkan nilai Pancasila dan melestarikan lingkungan sekitar. Metode Pendidikan Kepramukaan adalah penyamapain pendidikan kepada peserta didik melalui kegiatan Pendidikan Pramuka yang menarik, menyenangkan dan menantang, yang disesuaikan lingkungan sekitar, suasana pada kegiatan peserta didik.

Saran ini dapat diketahui pembentukan krakter siswa sekolah dasar Pacar Keling 1
Surabaya diharapkan dapat mengetahui pembentukan karakter gotong royong, siswa dapat dilakukan dalam kegiatan ekstrakurikuler kepramukaan.

1. Pembina Pramuka

Memberikan contoh keteladan bagi peserta didiknya dalam menanamkan karakter gotong royong dalam kegiatan latihan ekstra pramuka dengan melaksanakan kegiatan sabtu bersih, agar bisa diterapkan pada kehidupan sehari - hari dan dilingkungan sekitar.

\section{Siswa}

Siswa mentaati kegiatan ekstra pramuka yang diarahkan oleh kakak Pembina pramuka dapat mengikuti dengan penuh kesungguhan hati dan dapat mengaplikasikannya dalam kehidupan sehari - hari pada buku SKU dan SKK.

\section{Daftar Pustaka}

Alison Dolery Helen (2012) Making, happy, healty, helpful citizens: The New Zealand Scouting and Guiiding Movements as Promulgators of Active Citizenship, c.1908 - 1980. New Zealand: Massey University

https://mro.massey.ac.nz/bitstream/handle/10 179/4773/02_whole.pdf

Arif Mufti Habibi Muhammad.(2012) Penerapan Dasa Darma Pramuka Butir ke Delapan Dalam Membentuk Karakter 
Mahasiswa Melalui Pendidikan

Kepramukaan. Salatiga: UKM Pramuka

Rancana Kusuma Dilaga - Wiro

Srikandi IAN Salatiga

Arikunto, S. (2013). Prosedur Penelitian

Suatu Pendekatan Praktik. Jakarta:

Rineka Cipta.

Djamari (2016). Penanaman Sikap Gotong

Royong Dalam Kegiatan

Ekstrakurikuler Pramuka. Univeritas

Muhammadiyah Surakarta: Program

Studi Magister Administrasi Pendidikan

Sekolah Pascasarjana

http://eprints.ums.ac.id/44118/29/08\%20FUL

\section{L\%20TEKS.pdf}

Drs. H. Abdul Shobur, SH, MM, 2013,

Angaran Dasar dan Anggaran Rumah

Tangga Gerakan Pramuka : Kwartir

Nasional Gerakan Pramuka
Dharma, Kesuma. (2012). Pendidikan

Karakter Kajian Teori dan Praktik di

Sekolah. Bandung: PT Remaja

Rosdakarya

$\underline{\text { http://e- }}$

repository.perpus.iainsalatiga.ac.id/1535/1/SK

RIPSI-HABIBI.pdf

D,Imtihana. (2014). PENGEMBANGAN
SEBAGAI SUMBER. Unnes Journal of

Biology Education, 189.

Mafardi, (2017) Nilai - nilai karakter dalam mata pelajaran muatan lokal budaya alam. Sumatra: FKIP Muhammadiyah Sumatra

Peraturan Menteri Pendidikan dan Kebudayaan Republik Indonesia Nomor 81A Tahun 2013. IMPLENTESSI PENDIDIKAN:26

Prof. Dr. Sugiyono (2012). Metode Penelitian Kuantitatif, Kualitatif dan $R \& D$. Bandung: Alfabeta CVT

Prof. Dr. Syawal Gultom, M.Pd. (2014).

Kepramukaan Bahan Ajar Implementasi Kurikulum 2013. Jakarta: Pusat Pembangan Tenaga Kependidikan Badan Pengembangan Sumber daya Manusia Pendidikan dan Peminjaman Ramadhani Katrina (2019). Pengaruh Ekstrakurikuler Pramuka terhadap Karakter Mandiri, Integritas dan Nasionalisme pada Siswa Sekolah Dasar: Universitas Semarang https://lib.unnes.ac.id/35270/1/UPLOAD_KA TRINA_RAMADHANI.pdf

BUKLET BERBASIS PENELITIAN 